\title{
EDITORIAL
}

\section{The stability of fish populations: how changes in the environment may affect people with epilepsy}

\author{
Roberta M. Cysneiros,' Ricardo M. Arida," Vera C. Terra,"' Mariana B. Nejm,' ${ }^{\text {IV }}$ Fulvio A. Scorza ${ }^{\text {IV }}$ \\ 'Programa de Pós-Graduação em Distúrbios do Desenvolvimento do Centro de Ciências Biológicas e da Saúde da Universidade Presbiteriana Mackenzie. \\ SP, Brazil. "Departamento de Fisiologia. Universidade Federal de São Paulo/Escola Paulista de Medicina (UNIFESP/EPM). São Paulo, Brazil. "'Centro de \\ Cirurgia de Epilepsia (CIREP). Departamento de Neurociências e Ciências do Comportamento. Faculdade de Medicina de Ribeirão Preto, Universidade de

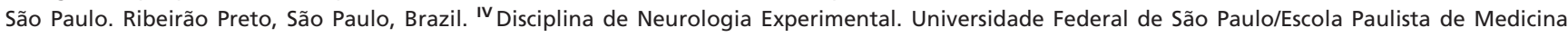 \\ (UNIFESP/EPM). São Paulo, Brazil.
}

The association between fish consumption and low rates of cardiovascular disease was studied nearly 40 years ago in the seafood diets consumed by Greenland Eskimos, Alaskan Natives and Japanese people residing in fishing villages.[1 Omega-3 fatty acids (from fatty fish in the human diet) also appear effective on the functioning of the brain. ${ }^{2}$ Furthermore, it is interesting to note that, of all organs in the human body excluding adipose tissue, the central nervous system (CNS) has the highest lipid content; for instance, approximately $50 \%$ of fatty acids are polyunsaturated in the gray matter, a third of which are of the omega- 3 family, and are thus dietary in origin. ${ }^{2}$ In humans, the intake of omega- 3 fatty acids, commonly found in fish and fish oil, not only contributes to CNS development but also plays a role in achieving optimal health and in the protection against certain adult CNS diseases. ${ }^{2}$ With respect to CNS disorders, epilepsy occupies a prominent place in this scenario.

Epilepsy is considered one of the most prevalent neurological conditions and approximately 50 million people worldwide are affected. ${ }^{3}$ From an epidemiological point of view, it must be acknowledged that most patients who develop epilepsy will go into remission, whilst remaining patients continue to have seizures and are refractory to treatment with the currently available therapies. ${ }^{4}$ Despite great advances in pharmacological treatment of epilepsy, anti-epileptic drugs are not completely effective in controlling seizures of patients with epilepsy. As such, dietary management, with particular emphasis on omega-3 fatty acids, is often tried by neurologists to control seizures in patients with epilepsy. The results of the first randomized trial of omega-3 fatty acids supplementation in patients with chronic epilepsy were encouraging, demonstrating a transient effect on seizure control. ${ }^{5}$ Although these results did not totally confirm that omega-3 fatty acids supplementation reduced the frequency of epileptic seizures in patients with refractory epilepsy, they established the safety of omega-3 fatty acids supplementation in people with epilepsy. ${ }^{5}$ From an experimental point of view, our research group was the first to demonstrate that chronic treatment

Email: scorza.nexp@epm.br

Tel.: $55115549-2064$

Copyright (c) 2011 CLINICS - This is an Open Access article distributed under the terms of the Creative Commons Attribution Non-Commercial License (http:// creativecommons.org/licenses/by-nc/3.0/) which permits unrestricted noncommercial use, distribution, and reproduction in any medium, provided the original work is properly cited. with omega-3 promotes neuroprotection and positive plastic changes in the brain of rats with epilepsy. ${ }^{6}$

Considering the potential health benefits of fish consumption and the positive effects of omega-3 supplementation in various CNS diseases, an intriguing question arose: should neuroscientists be concerned with the changes in the structure and abundance of fish fauna? Yes, they should be. Why?

Firstly, it is widely accepted that there is a severe problem with future global food supply and security. ${ }^{7}$ Fish consumption has increased substantially and, for this reason, several fish populations are being devastated and unable to produce their maximum sustainable yields. ${ }^{7}$ Unfortunately, illegal, unreported and unregulated (IUU) fishing contributes to overexploitation of fish stocks and is a hindrance to the recovery of fish populations and of the whole ecosystem. ${ }^{7}$ Furthermore, it is also important to note that IUU has a direct impact on annual economic benefits $(\$ 10$ bn and $\$ 23.5$ bn annually, representing between 11 and 26 million tons). ${ }^{7}$

Secondly, according to the World Fisheries and Aquaculture 2008 report by the Food and Agriculture Organization of the United Nations, $80 \%$ of all marine fish stocks for which assessment information is available are fully exploited or overexploited. ${ }^{8}$ According to Conover and colleagues, the evolutionary responses to commercial fishing might be causing genetic changes in the fish that swim in the ocean, reducing growth rate, age at maturation, body size and productivity. ${ }^{9}$ Importantly, the researchers demonstrated that taking too many large fish out of a population leads to the birth of smaller fish over time. ${ }^{9}$

Thirdly, although we are only at the early stage in the projected trends of global warming, ecological responses (e.g. fluctuations in marine fish populations) to recent climate change are already clearly visible. ${ }^{10}$ The Earth's climate has warmed by approximately $0.6^{\circ} \mathrm{C}$ over the past 100 years with 2 main periods of warming between 1910 and 1945 and from 1976 onwards, and it is now clear that these recent climatic changes have affected the abundance and diverse geographical distributions of marine fish. ${ }^{10}$ Unfortunately, the evidence described until now indicates that only 30 years of warmer temperatures at the end of twentieth century have affected the phenology (the time of seasonal activities of animals and plants) of the marine fish populations, the range and distribution of fish species, and the composition and dynamics of fish communities. ${ }^{10,11}$

Lastly, is quite clear that fish diets are extremely healthy for us all; however, some fish contain contaminants that we 
would rather not be eating. As we know, the major risk of fish consumption is mercury content. In general, mercury enters the atmosphere by combustion (mainly waste and coal) following which, it enters the oceans where it is converted to methylmercury by microorganisms and taken up by marine life and concentrated in fish tissues. As methylmercury is strongly neurotoxic and its consumption a risk to health: are we totally safe eating fish? As the concentration of methylmercury in fish is increased in predatory fish than non-predatory fish, the best seafood choices are those with non-predatory characteristic. Thus, we can say that anchovies, Atlantic herring, Atlantic mackerel wild salmon, sardines and trout have low levels of methylmercury, whereas tuna, shark, tilefish and swordfish have high levels of methylmercury. ${ }^{12-14}$ For individuals who want a diet with zero methylmercury but would like to enjoy the benefits of omega- 3 fatty acids, there are always fish oil supplements or other foods such as walnuts or oils (flax, canola and soybean). ${ }^{13,15}$

Taking all this into consideration, what have we really learned and what we do from now on? Modern science recognizes the positive health effects of fish diets. With regards to epilepsy, a number of different dietary modifications and nutritional supplements may help prevent seizures or improve other aspects of health in patients with epilepsy. In particular, our research group is quite convinced that omega- 3 fatty acids are very important for the normal functioning of the brain and is useful in the prevention and treatment of epilepsy. Most of all, in order to create conditions for the survival of finfish and shellfish species; we are sure that environmental political measures are necessary. Most importantly, we would bring together neuroscientists and ecologists to begin a translational science between the two fields in order to transform scientific studies into clinical applications to reduce the incidence of disease, morbidity and mortality in the human population worldwide. The connection between the two disciplines could begin linking health and ecology in the medical curriculum, which already has excellent acceptance and applicability in some universities around the world. ${ }^{16}$

We are totally in agreement with Zinsstag and colleagues warning us that time is short and that climate change and resource depletion will become visible at an accelerated pace. ${ }^{17}$ Like us, these authors also believe that solutions require all the possible intellectual imagination of science and technology and, at the same time, new and aggressive environmental political measures.

\section{REFERENCES}

1. He K. Fish, long-chain omega-3 polyunsaturated fatty acids and prevention of cardiovascular disease eat fish or take fish oil supplement? Prog Cardiovasc Dis. 2009;52:95-114, doi: 10.1016/j.pcad.2009.06.003.

2. Bourre JM. Omega-3 fatty acids in psychiatry. Med Sci. 2005; 21:216-21.

3. Sander JW. The epidemiology of epilepsy revisited. Curr Opin Neurol. 2003;16:165-70, doi: 10.1097/00019052-200304000-00008.

4. Kwan P, Sander JW. The natural history of epilepsy: an epidemiological view. J Neurol Neurosurg Psychiatry. 2004;75: 1376-81, doi: 10.1136/ jnnp.2004.045690.

5. DeGiorgio CM, Miller P. n-3 fatty acids (eicosapentanoic and docosahexanoic acids) in epilepsy and for the prevention of sudden unexpected death in epilepsy. Epilepsy Behav. 2008;13:712-3, doi: 10.1016/j.yebeh. 2008.06.017.

6. Ferrari D, Cysneiros RM, Scorza CA, Arida RM, Cavalheiro EA, Almeida ACG et al. Neuroprotective activity of omega-3 fatty acids against epilepsy-induced hippocampal damage: quantification with immunohistochemical for calcium-binding proteins. Epilepsy Behav. 2008;13:3642, doi: 10.1016/j.yebeh.2008.01.001.

7. Agnew DJ, Pearce J, Pramod G, Peatman T, Watson R, Beddington JR et al. Estimating the worldwide extent of illegal fishing. PLoS One. 2009;4:e4570, doi: 10.1371/journal.pone.0004570.

8. Tibbetts J. Natural resources: reversing human impacts on fish evolution. Environ Health Perspect. 2009;117:A197.

9. Conover DO, Munch SB, Arnott SA. Reversal of evolutionary downsizing caused by selective harvest of large fish. Proc Biol Sci. 2009;276:2015-20, doi: 10.1098/rspb.2009.0003.

10. Walther GR, Post E, Convey P, Menzel A, Parmesan C, Beebee TJ et al. Ecological responses to recent climate change. Nature. 2002;416:389-95, doi: $10.1038 / 416389$ a.

11. Ojaveer E, Lehtonen H. Fish stocks in the Baltic Sea: finite or infinite resource? Ambio. 2001;30:217-21.

12. Scorza FA, Cysneiros RM, Arida RM, Terra VC, Machado HR, Rabello $\mathrm{GM}$ et al. Fish consumption, contaminants and sudden unexpected death in epilepsy: many more benefits than risks. Braz J Biol. 2010;70:665-70.

13. Jeejeebhoy KN. Benefits and risks of a fish diet should we be eating more or less? Nat Clin Pract Gastroenterol Hepatol. 2008;5: 178-9, doi: 10.1038/ ncpgasthep1067.

14. Smith KM, Sahyoun NR. Fish consumption: recommendations versus advisories, can they be reconciled? Nutr Rev. 2005;63:39-46, doi: 10.1111/ j.1753-4887.2005.tb00120.x.

15. Domingo JL. Omega-3 fatty acids and the benefits of fish consumption: is all that glitters gold? Environ Int. 2007;33:993-8, doi: 10.1016/j.envint. 2007.05.001.

16. Rapport DJ, Howard J, Lannigan R, McCauley W. Linking health and ecology in the medical curriculum. Environ Int. 2003;29:353-8, doi: 10. 1016/S0160-4120(02)00169-1.

17. Zinsstag J, Schelling E, Waltner-Toews D, Tanner M. From "one medicine" to "one health" and systemic approaches to health and wellbeing. Prev Vet Med. 2011; Epub ahead of print: DOI 10.1016/ j.prevetmed.2010.07.003. 